\title{
Thermogravimetry-evolved gas analysis-mass spectrometry system for materials research
}

\author{
M KAMRUDDIN, P K AJIKUMAR, S DASH, A K TYAGI and BALDEV RAJ* \\ Metallurgy and Materials Group, Indira Gandhi Centre for Atomic Research, Kalpakkam 603 102, India
}

MS received 13 May 2002

\begin{abstract}
Thermal analysis is a widely used analytical technique for materials research. However, thermal analysis with simultaneous evolved gas analysis describes the thermal event more precisely and completely. Among various gas analytical techniques, mass spectrometry has many advantages. Hence, an ultra high vacuum (UHV) compatible mass spectrometry based evolved gas analysis (EGA-MS) system has been developed. This system consists of a measurement chamber housing a mass spectrometer, spinning rotor gauge and vacuum gauges coupled to a high vacuum, high temperature reaction chamber. A commercial thermogravimetric analyser (TGA: TG + DTA) is interfaced to it. Additional mass flow based gas/vapour delivery system and calibration gas inlets have been added to make it a versatile TGA-EGA-MS facility. This system which gives complete information on weight change, heat change, nature and content of evolved gases is being used for (i) temperature programmed decomposition (TPD), (ii) synthesis of nanocrystalline materials, (iii) gas-solid interactions and (iv) analysis of gas mixtures. The TPD of various inorganic oxyanion solids are studied and reaction intermediates/products are analysed off-line. The dynamic operating conditions are found to yield nanocrystalline products in many cases. This paper essentially describes design features involved in coupling the existing EGA-MS system to TGA, associated fluid handling systems, the system calibration procedures and results on temperature programmed decomposition. In addition, synthesis of a few nanocrystalline oxides by vacuum thermal decomposition, gas analysis and potential use of this facility as controlled atmosphere exposure facility for studying gas-solid interactions are also described.
\end{abstract}

Keywords. Evolved gas analysis; thermogravimetry; mass spectrometry; temperature programmed decomposition; gas-solid interaction; nano-materials.

\section{Introduction}

Thermogravimetric analysis covers a wide spectrum of thermoanalytical techniques, which monitor one or more physical properties of a substance that is undergoing a temperature programmed heating as a function of time or temperature. Though the thermogravimetric analyser (TGA) system, which combines thermogravimetry (TG) and differential thermal analysis (DTA), is widely used in the fields of gas-solid interactions, fuels, catalysis, polymers and chemical synthesis, it is a limited technique. This method can not distinguish the actual nature of the material evolved in the course of the process and is also handicapped in resolving overlapped thermal events. So it is seldom able to describe the process under study completely. However, a simultaneous technique which can provide complementary information, particularly on the nature and content of the liberated product gases, will be able to describe the process more precisely, save analysis time and avoid variations in experimental conditions between samples. This simultaneous technique

\footnotetext{
*Author for correspondence
}

finds application in wide range of research activities and is used in analysing and characterizing wide variety of materials like coal, rocks and minerals (Heide et al 1997), rubbers, petroleum coke, hydrocarbon sludges from petrochemical plants (Remmler et al 1995), polyimide resin (Ozawa 2000), superconducting materials, hydrogen storage materials, fire retardant materials (Statheropoulos and Kyriakov 2000) and even moon rock. Apart from its traditional use in investigations of chemical reactions (Gallagher 1982), temperature programmed decompositions (Brown 1998), study of reaction kinetics and mechanisms (Ohrbach et al 1983), determination of material purity, stoichiometry etc this technique is also used in the areas of forensic science, archeology (Heide et al 2000), catalysis (Gorte 1996), polymers (Nielsen et al 1995) and pharmaceuticals.

A large number of gas analytical techniques like gas chromatography (Jemal and Khattech 1989), Fourier transform infrared spectroscopy (FT-IR) (Mullens et al 1992) and mass spectrometry (MS) (Price et al 1980; Barnes 1987) and sometimes combination of more than one of the above (Mullens et al 1997) are used for interfacing with TGA. However, mass spectrometry is a preferred choice for the analysis of evolved gases because of its 
advantages like high specificity, sensitivity, fast response, low detection limits, multiple ion and isotope detection capability. Among the different types of mass spectrometers, the quadrupole mass analyser (QMA) is widely used due to its added advantages like ease of operation, small size, easy system integration, peak hopping facility and low capital cost (Leskela et al 1993; Raemaekers and Bart 1997).

As the operating conditions of mass spectrometer (at pressures around or less than $1 \times 10^{-6} \mathrm{mbar}$ ) and TGA (normally under ambient or flowing conditions) are different, they need to be coupled through a proper pressure reduction system without affecting the chemistry of the evolved gases or introducing unacceptable time delays between release and detection. Though high vacuum is adequate for QMA operation, UHV condition will ensure low background, better sensitivity and lower detection limits. Hence, proper care at design stage, identification of matching components and suitable interface are prerequisites for optimized performance of a combined thermogravimetric, mass spectrometry based evolved gas analysis system. Such a system will provide a better understanding of the thermal event and will lead to unambiguous interpretation of the process. Evidently this technique has evolved from a laboratory curiosity to a state of proven, full-fledged analytical tool.

A modular and versatile combined system comprising of a TG/DTA, mass spectrometer based ultra high vacuum (UHV) compatible EGA-MS, mass flow controlled gas and water vapour delivery systems and a direct precursor/liquid delivery system has been designed and built to study high temperature gas-solid interactions and other applications. This system has been used to study the temperature programmed decomposition (TPD) of many oxyanion based inorganic salts, their reaction mechanisms, kinetics and to deduce their chemical-structural reaction pathways. It is being used for qualitative as well as quantitative analysis of unknown gas mixtures and pure gases with ppm level impurities. This system has also been used for synthesis of nanocrystalline materials like $\mathrm{CaO}, \mathrm{Al}_{2} \mathrm{O}_{3}, \mathrm{ThO}_{2}$ and $\mathrm{CeO}_{2}$ by decomposing appropriate precursors under vacuum. This paper describes the design details of this indigenously built system, its salient features and capabilities. It also briefly reports typical results obtained from this system, highlighting the applicability of this facility.

\section{Description of experimental facility}

The experimental facility essentially consists of a low thermal mass high temperature, high vacuum reaction chamber coupled to a UHV compatible quadrupole mass spectrometer (QMS) based evolved gas analyser (Kamruddin et al 1995), a high temperature TG/DTA system and a simple two-stage pressure reduction interface. This system is also provided with mass flow controlled gas delivery, vapour delivery system and a pulse free direct precursor/liquid injection system to control/alter the environment around the specimen. The gas and liquid delivery units enhance the system's capability to study the chemical reactions/synthesis in desired atmospheres, to produce novel coatings by gas-metal surface interaction. It also functions as a controlled atmosphere exposure facility for studies pertaining to oxidation of high temperature materials, surface modification and engineering.

\section{$2.1 U H V-E G A-M S$ system}

The UHV-EGA-MS system comprising of a reaction chamber coupled to a measurement chamber is described elsewhere (Dash et al 1997a). Hence, only a brief description, highlighting the recent additions, is given below. The reaction chamber is a high vacuum compatible quartz tube surrounded by a low thermal mass, resistance heated, high temperature $(2000 \mathrm{~K})$ platinum furnace $(\mathrm{M} / \mathrm{s} \mathrm{CM}$ Furnaces, USA) equipped with an autotune temperature programmer and a thyristor based power controller to achieve programmed heating (typical ramp rates of 1$15 \mathrm{~K} / \mathrm{min}$, up to $1400 \mathrm{~K}$, limited by softening temperature of quartz). One thermocouple, in conjunction with the temperature controller, is used for furnace temperature control and another kept in contact with the specimen holder is connected to a data acquisition system (34970A, $\mathrm{M} / \mathrm{s}$ Agilent) for direct recording of specimen temperature. Membrane manometer and vacuum gauge are also provided in this chamber for pressure measurement.

The UHV-MS measurement system is an all metal, bakeable stainless steel chamber pumped by a combination of a sputter ion pump, a titanium sublimation pump and backed by a turbo molecular pumping unit. It operates at a base pressure of $1 \times 10^{-10} \mathrm{mbar}$ and at $5 \times$ $10^{-9}$ to $1 \times 10^{-8}$ mbar during analysis. This high vacuum level ensures low background, better sensitivity and lower detection limits. This chamber houses a 1-300 amu (HAL 2C, M/s Hiden, UK) quadrupole mass spectrometer with an electron impact ionization source having a partial pressure detection limit of $1 \times 10^{-14}$ mbar, an inverted magnetron gauge (IMG) and a spinning rotor viscosity gauge (SRG) for absolute pressure measurement and calibration. Molecular leak valves are provided as gas inlets for calibration, quantitative analysis of unknown gas mixtures and for evolved gases from reaction chamber and TGA. This is coupled to the reaction chamber through a heated gas line (to avoid condensation of condensable vapour) and a variable conductance molecular leak valve to bleed controlled quantities of representative evolved gases for mass spectrometric analysis. The QMS, interfaced to a personal computer, tracks the ion intensities of up to 16 selected gases of interest as a function of time and/or specimen temperature. The scan 
time of $\sim 1 \mathrm{msec} / \mathrm{channel}$ of QMS allows acquisition of instantaneous and quasi-continuous spectra of evolved gases.

In the reaction chamber, small quantities of the powdered specimen (typically 50 to $200 \mathrm{mg}$ ) taken in an alumina/platinum crucible are program heated either in vacuum or in a flowing gas (inert/active) stream. The gases evolved due to temperature induced reactions/decomposition are fed to the UHV chamber for on-line analysis. The continuous change in ion intensities of product gases is plotted as a function of specimen temperature to generate the EGA-MS spectra.

This EGA-MS system can operate in four different modes: (i) for temperature programmed decomposition, (ii) controlled synthesis of nanocrystalline materials, (iii) gas-solid interactions under controlled atmosphere and pressure and (iv) for qualitative and quantitative analysis of unknown gas mixture (Dash et al 1997a; Kamruddin et al 2002).

\subsection{The TGA system}

A high temperature TGA system (SETSYS 16/18, M/s Setaram, France), having a temperature range of ambient to $2000 \mathrm{~K}$ and maximum sample size and resolution of $20 \mathrm{~g}$ and $0.04 \mu \mathrm{g}$, respectively, is appended to EGA-MS to get complementary information like mass and heat change. It is a bottom loading system with provisions for flow of carrier gas and an auxiliary gas around the specimen. The evolved gas take-off tube is kept close to the specimen cup. In bottom loading machines, the opposing carrier gas flow and upward convection flow of hot evolved gases lead to better mixing and prompt removal of evolved gases to ensure a representative sampling and reduces the unwanted recombination reactions, delay in analysis and memory effects. Hence, a vertical, bottom loading system was chosen for the integration. Typical sample sizes used are 2-20 mg with heating rates 2-15 $\mathrm{K} / \mathrm{min}$ at carrier gas flow of $45-125 \mathrm{ml} / \mathrm{min}$.

\subsection{TGA-MS interface}

Different types of purpose built interfaces are reported in the literature (Dollimore et al 1984; Charsley et al 1987). The essential design criteria for a TGA-MS interface is that it should be simple, flexible and let a small portion of the evolved gases bleed to the mass spectrometer in a reproducible and quantitative manner for continuous monitoring. It should not introduce any time delay, excessive dilution and memory effect. It should also ensure the different pressure conditions and requisite flow behaviour involving laminar at the TGA side for faster transfer and molecular at mass spectrometric side for representative sampling.

Keeping this in mind, a simple two-stage pressure reduction interface was designed and implemented. It basically consists of a take-off tube placed very close to the specimen crucible in the TGA, a narrow and heated passage tube for gas transfer without condensation. This tube terminates with a micrometering valve connected to a rotary pump. This acts as the first stage of pressure reduction and gives the desired viscous flow required for faster transfer. The second stage of pressure reduction is achieved through a molecular leak valve. This ensures both a clean sample entry and the low operating pressure at the mass spectrometer. With optimized interface geometry and by adjusting these two valves, typical pressures in the range of a few mbar at first stage and $10^{-8}$ mbar or better in the second stage are achieved.

For gas analysis, the evolved gases may be transferred to the UHV measurement chamber or to avoid loading the system with inert carrier gas, the evolved gases may be let into another high vacuum system for analysis. This is also an all metal, bakeable system pumped by a turbomolecular pumping unit $(300 \mathrm{l} / \mathrm{sec})$ and operates at a base pressure of $1 \times 10^{-8} \mathrm{mbar}$. It houses a quadrupole mass spectrometer (1-300 amu, M/s Hiden, UK) and vacuum gauges. Though the operating pressure is relatively higher in this system, it is more suitable for pumping inert carrier gases, for faster and routine work. However, for more accurate analyses and lower detection limits the UHV system is used. A schematic of TGA interfaced to high vacuum system is shown in figure 1 .

\subsection{Delivery systems}

The gas inlet side of the TGA system is provided with a bank of four mass flow controllers (10-1000 sccm), a gas blender and a baratron pressure transducer to provide a desired gas mixture of required composition to flow past the specimen. The TGA system is additionally provided with a water vapour delivery system (WVDS). This system is used to introduce and maintain a controlled humidity in the TGA chamber around the specimen. This system consists of a water bottle to generate the humid gas. By maintaining the temperature of this water bottle, with an accuracy of $\pm 0 \cdot 1^{\circ} \mathrm{C}$, by a constant temperature bath, a desired water vapour pressure in the auxiliary gas can be achieved. The humid gas thus generated is transferred to the TGA through a thermostated gas line. The gas line and entry points in the TGA are maintained by another thermostated water bath at a temperature $10^{\circ} \mathrm{C}$ higher than the water bottle temperature to avoid any condensation in the line. This arrangement is very useful in studying the reactions under humid conditions, Smith Toplay effect and to investigate the effect of water vapour on the oxidation behaviour of technically relevant structural materials by exposing them to more real service conditions (Janakiraman et al 1999). The gas-solid interactions and the associated transformations can be followed on-line by TGA-EGA-MS. 
The studies on oxidation mechanism of, for e.g. alumina formers like TiAl (Kamruddin et al 2000), are difficult due to their low oxidation rates and complex transport processes in the oxide scales. The transport involves the diffusion through preferred paths as well as the changes in the phase composition of the scale during transient oxidation. Different diffusion processes dominate in various co-existing oxide phases. Direct evidence of the transport mechanism in the scale is normally obtained by two-stage oxidation experiments using ${ }^{18} \mathrm{O}$ as a tracer (Akermark 1998). However, direct gas phase analysis along with mass gain data during the two-stage oxidation is essential to understand the oxidation mechanism (Jedlinski and Borchardt 1991).

A direct precursor delivery system (DPDS) which will provide a pulse free and quantitative delivery of fluids and liquid precursors $(0.006$ to $2.5 \mathrm{cc} / \mathrm{min})$ to TGA system is also incorporated. This system consists of a leak tight $\left(1 \times 10^{-9} \mathrm{scc} / \mathrm{sec} \mathrm{He}\right)$ S.S. source container, a liquid delivery system (DLI-25, M/s MKS Inc., USA) which comprises of a micro pump, a flash vapouriser and control electronics and other pressure and flow control baratrons and mass flow controllers. As the liquid is not exposed to heat in the delivery line it eliminates decomposition of heat sensitive precursors. So organometallic precursors can be sublimed in the DPDS and vapours can be fed to the TGA-MS system in a controlled manner. This vapour will dissociate at the specimen surface maintained at high temperature to form the desired coating. On-line TGA measurements can be used to study the growth process, its kinetics and integrity of such coatings or thermally grown overlayers (TGO). A schematic of the complete TGA-EGA-MS system is given in figure 2 .
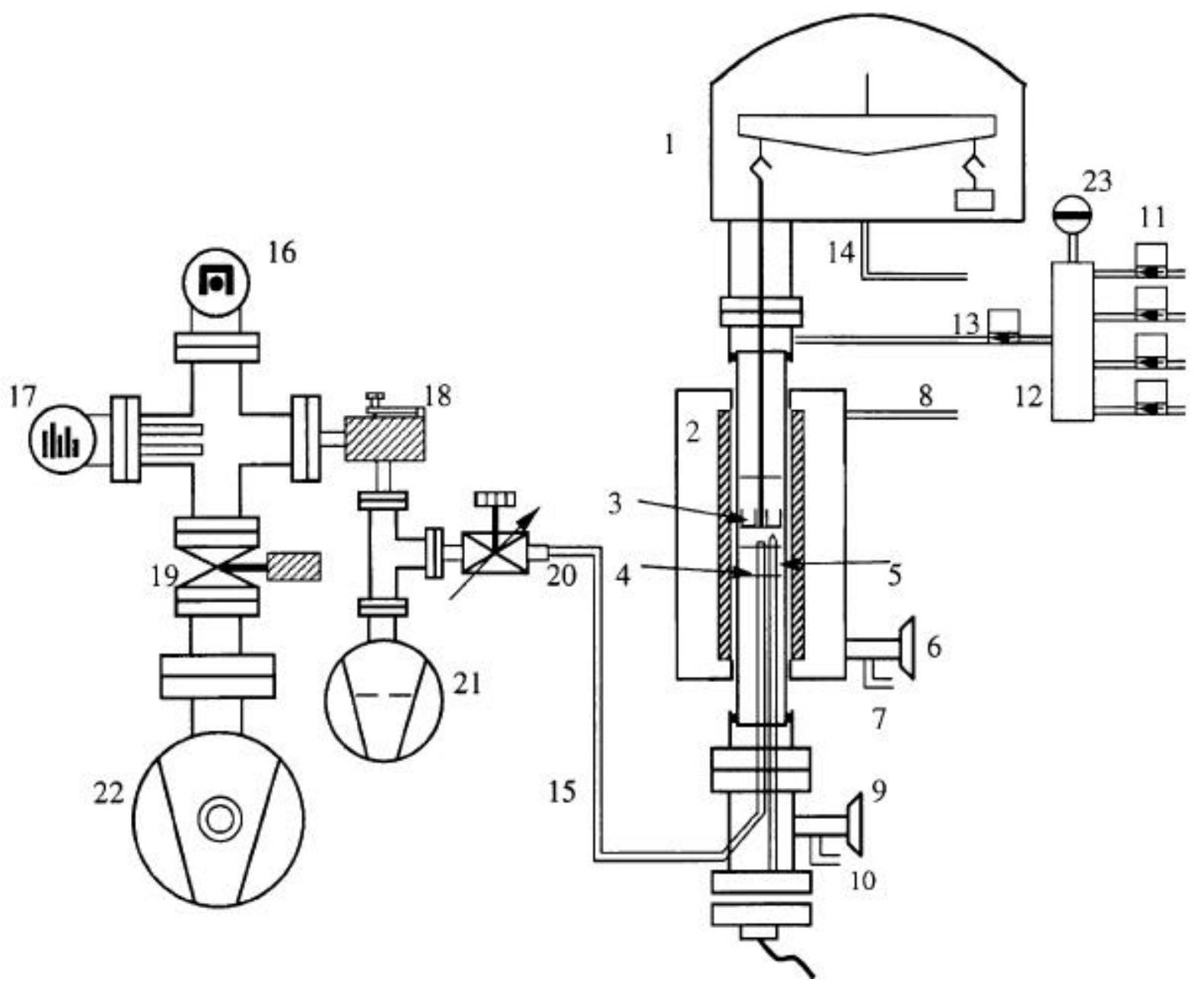

1. Microbalance; 2. TGA furnace; 3. Specimen in TG/DTA rod; 4. Gas take off tube; 5. Control thermocouple; 6,9. To vacuum pump; 7. Furnace protection gas - inlet; 8. Furnace protection gas - outlet; 10. Carrier and auxiliary gas outlet; 11. Mass flow controllers; 12. Gas blender; 13. Auxiliary gas inlet; 14. Inert carrier gas inlet; 15. Heated gas line to MS; 16. Magnetron gauge; 17. Quadrupole mass analyser; 18. Molecular leak valve; 19. Gate valve; 20. Micrometering valve; 21 . Rotary pump; 22. Turbo molecular unit; 23. Baratron.

Figure 1. Schematic diagram of thermogravimetric analyser-mass spectrometry system (TGA-MS). 


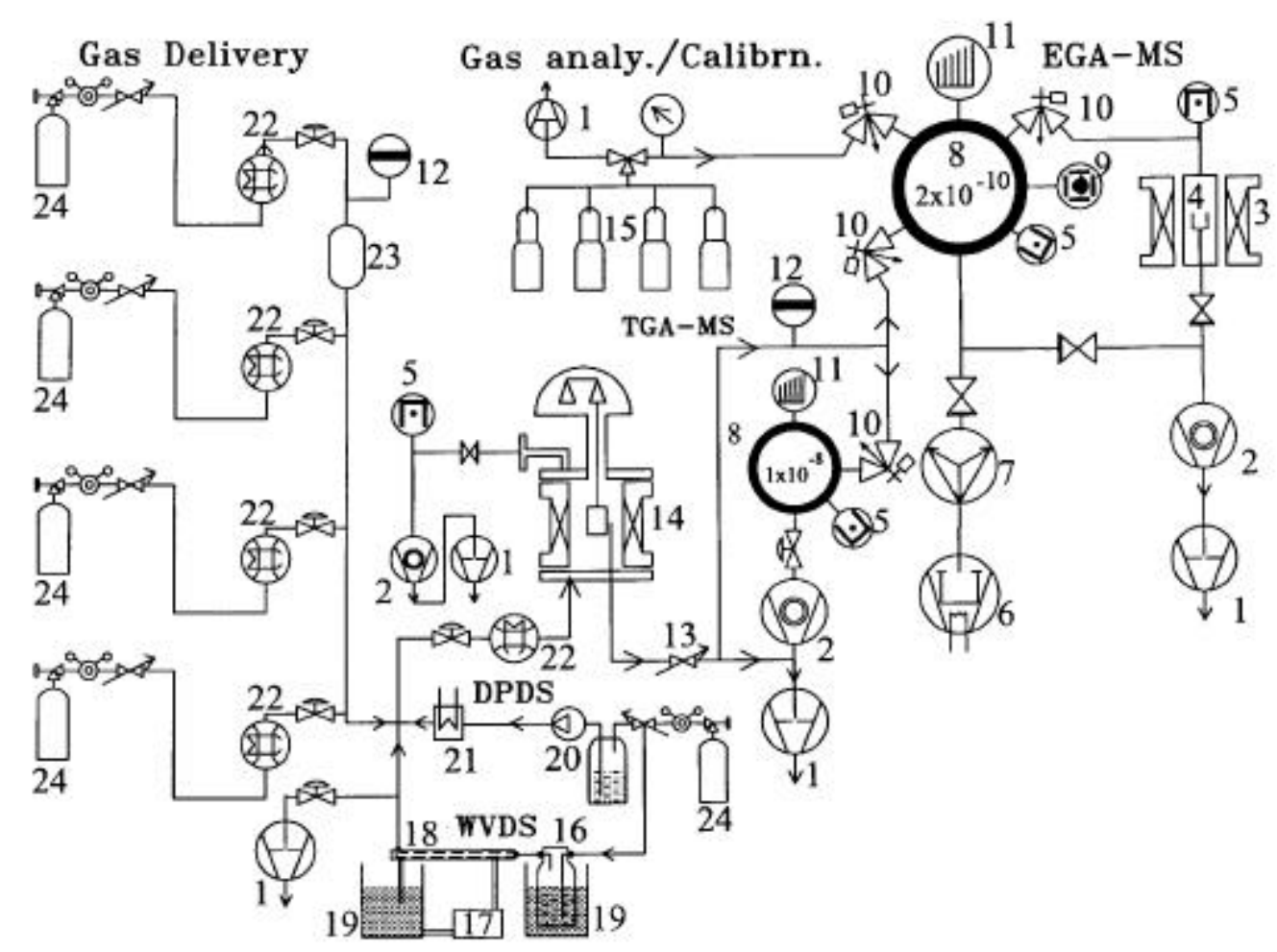

1. Rotary pump

2. Turbo pump

3. Furnace

4. Reaction chamber

5. Magnetron gauge

6. Sublimation pump

7. Sputter ion pump

8. Measurement chamber

9. SRG

10. Leak valve

11. QMA

12. Baratron

13. Metering valve

14. TGA

15. Calibration gases

16. Water container

17. Circulation pump

18. Thermostated gas line

19. Thermostat

20. Source container

21. Vapourizer

22. MFC

23. Gas blender

24. Gas cylinder

Figure 2. Schematic diagram of TGA-EGA-MS facility.

\section{System calibration/standardization}

\section{$3.1 \quad E G A-M S$ system}

Calibration of EGA-MS equipment is performed by three different methods, viz. (a) controlled bleeding of known quantities of gas into the vacuum chamber through a variable, low conductance molecular leak valve, (b) using a spinning rotor viscosity gauge (SRG) as a primary standard pressure measuring device and (c) by carrying out TPD of well documented stoichiometric reactions.

3.1a Gas dosing method: An ultrahigh vacuum compatible variable conductance molecular leak valve (MD 7 , $\mathrm{M} / \mathrm{s}$ VG micromass, UK) was used for bleeding known quantities of gases into the UHV chamber. A capacitance manometer working in the range 1-5000 mbar is used to measure the inlet gas pressure. Calibration gases were leaked in for fixed times to generate rectangular shaped dosing profiles (figure 3a). The number of molecules leaked in, calculated from the throughput, are directly proportional to the area inscribed by the MS signal (figure $3 b$ ). The proportionality constant is calculated from the slope of the curve.

3.1b Absolute pressure measurement using SRG: The QMS signal is dependent on the gas specific physical property, viz. the ionization probability. The ion current measured by the QMS can be expressed as

$$
i_{+}=i_{-} \sigma \lambda p,
$$

$i_{+}$refers to the ion current, $i_{-}$the electron current, $\sigma$ the ionization cross-section, $\lambda$ the mean free path and $p$ the gas pressure. The sensitivity factor $i_{-} \sigma \lambda$ can be accurately determined if the pressure $p$ can be measured with an absolute pressure gauge. SRG shown in figure $3 c$, is an absolute pressure gauge, which is used to measure the absolute pressure in the vacuum system (Fremory and Boden 1978). Typical calibration plots for IMG and QMS, generated using this gauge are shown in figure $3 \mathrm{~d}$.

3.1c Decomposing model substances: In this method, different amounts of model substances (e.g. copper sulphate pentahydrate, calcium carbonate, calcium oxalate) with well known stoichiometric thermal decomposition are heated and the evolved gases are continuously monitored. These compounds decompose at well defined temperatures through resolved substages to release water and other product gases over a wide temperature range of interest. The stoichiometric weight change after the decomposition is correlated to the MS signal and the peak position indicates the time delay, if any, between the reaction and its detection.

\subsection{TGA system}

The TGA system was calibrated for temperature accuracy and DTA heat flow by carrying out the endothermic melt- 
ing of pure metals like $\mathrm{In}, \mathrm{Sn}, \mathrm{Pb}, \mathrm{Zn}, \mathrm{Al}, \mathrm{Ag}, \mathrm{Au}, \mathrm{Ni}$ and $\mathrm{Pd}$ which cover the broad temperature range (430$1800 \mathrm{~K}$ ) of our interest. The temperature programmed decomposition of model substances like copper sulphate and calcium oxalate were carried out in different operating conditions like heating rates, sample mass, carrier gas and its rate of flow to standardize the system.

\subsection{TGA-EGA-MS system}

The standardization of TGA-EGA-MS was mainly carried out to optimize the interface conditions and to obtain ideal operating parameters to achieve best possible results with minimum time delay, better resolution and sensitivity (Kaisersberger and Post 1997). The operating parameters like heating rate, sample mass and carrier flow gas were systematically varied to study their individual as well as collective effect on the MS signal and its reproducibility.

3.3a Effect of heating rate: Normally, the QMS signal should not be affected by the heating rates as the stoichiometry of the reaction and thus the amount of gas evolved in the reaction are not affected by it. However, it does affect the onset of the reaction and also its temperature span. Slower heating rates will lead to spread in the gas release and higher dilution by carrier gas and thus lowering the overall sensitivity. The variation in heating rates is useful in resolving the overlapped thermal events. The QMS signal is also affected by the temperature rise in the TGA due to the change of density and viscosity of the released gases. Hence, the heating rate has to be judiciously fixed to get optimum results for a given system. The variation in the area of QMS signal as a function of heating rate is shown in figure $4 \mathrm{a}$.

3.3b Mass variation: Mass spectrometric signal shows an increasing trend with the sample mass. It has been reported that the MS signal was linear even for a ten-fold increase in the sample mass (Maciejewski and Baiker 1997). The change in area of QMS signal as a function of sample mass for two different heating rates is shown in figure $4 \mathrm{~b}$. The increase in sample mass is useful in detection and analysis of trace releases. However, higher sample mass will lead to temperature gradient within the sample as well as between the crucible wall and the sample and offers longer diffusional paths for the released gases. This will also lead to shift in onset and peak temperature to higher temperatures and peaks with longer tails.

3.3c Carrier gas and its flow rates: The carrier gas used was helium as it is inert and difficult to ionize and will not interfere with the mass spectra of the evolved product gases. Its high thermal conductivity ensures better temperature uniformity. Helium is also inert to charge exchange and ion/molecule reactions with product gases.

A high degree of gas flow stability and control is necessary to produce calibration curves and to ensure reproducibility in actual experimental runs. Though the carrier gas dilutes the product gases, it is required to sweep these gases to the mass spectrometer. The lower flow rates will give a lesser dilution but will lead to higher hold-up times as it will not be able to sweep the evolved gases swiftly and can lead to considerable time (a)

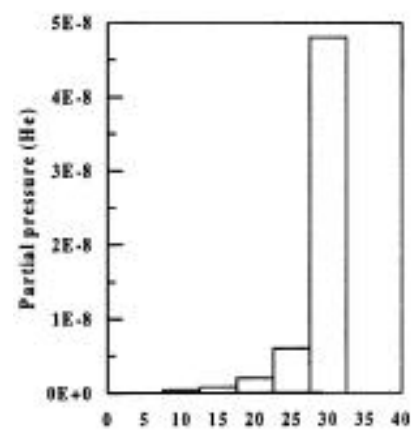

(c)

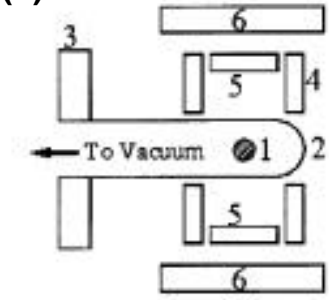

1. Spinning Ball 2. Vacuum tube 3. Vacuum flange 4. Vertical coil 5. Drive coils 6. Magnets

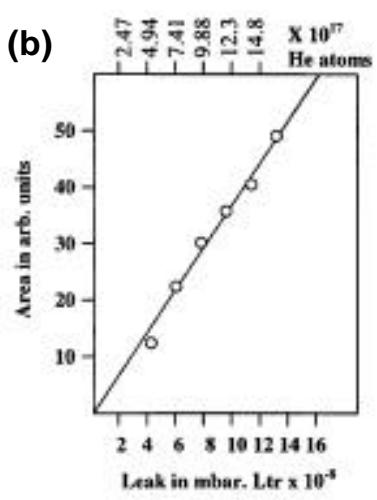

(d)

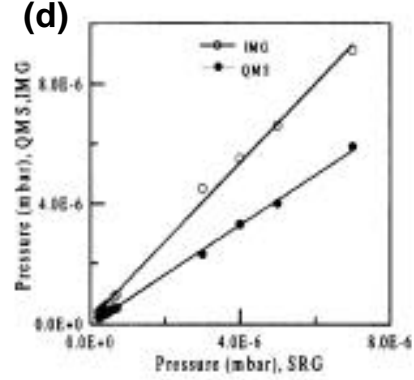

Figure 3. (a) Typical gas dosing profile, (b) corresponding calibration plot, (c) schematic of SRG and (d) calibration plots of IMG and QMA.
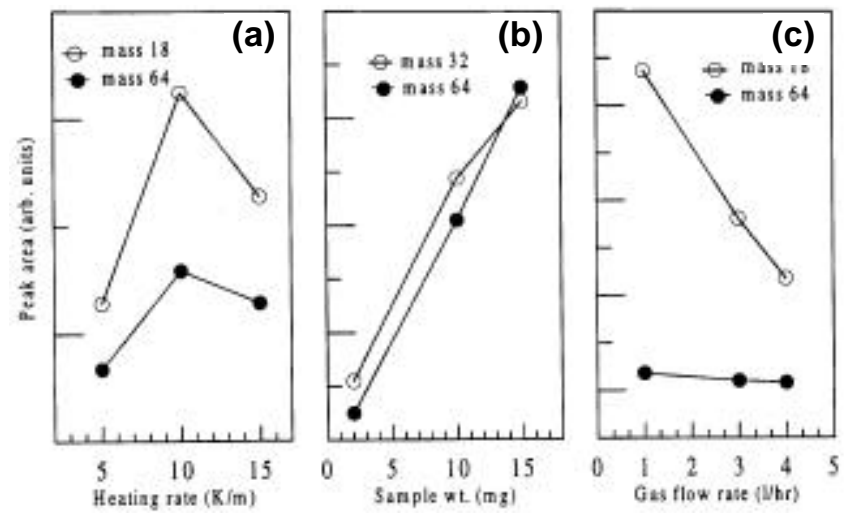

Figure 4. Effect of operating parameters on MS signal of TPD of copper sulphate: (a) heating rate, (b) sample mass and (c) carrier gas flow rate. 
delay between the thermal event and the gas detection. This will also give unacceptable tailing effect. On the other hand, higher flow rates will sweep the evolved gases swiftly but at the expense of larger dilution and lower sensitivity. A decrease in the area of the QMS signal as a function of carrier gas flow rate is shown in figure $4 \mathrm{c}$. Much higher flow rates may even give turbulent motion within the TGA system and can impair the weight measurement. So any hyphenated system will need optimization of carrier gas flow rates according to mass of the sample, mass change of the reaction and the heating rate.

\subsection{System's performance optimization}

After carrying out the TGA-MS run at different operating conditions, the optimum parameters were identified for the present system configuration. The TGA-EGAMS spectrum of TPD of $2 \mathrm{mg}$ of $\mathrm{CuSO}_{4} \cdot 5 \mathrm{H}_{2} \mathrm{O}$ performed under optimized conditions, with a flow rate of $90 \mathrm{ml} /$ min of He is shown in figure 5. The last weight change of $\sim 3 \%(\sim 0.06 \mu \mathrm{g}$ weight change) at $1060 \mathrm{~K}$, corresponding to conversion of $\mathrm{CuO}$ to $\mathrm{Cu}_{2} \mathrm{O}$, the mass spectrometer could generate a fairly big $\mathrm{O}_{2}$ peak (corresponding $\mathrm{Y}$-axis in a.u. is not shown in figure 5). There was good correlation between weight change and gas release with no observable time lag between them and in fact most of the mass change stages were observed at on-line mass spectrum before it could be detected in the TGA weight change curve.

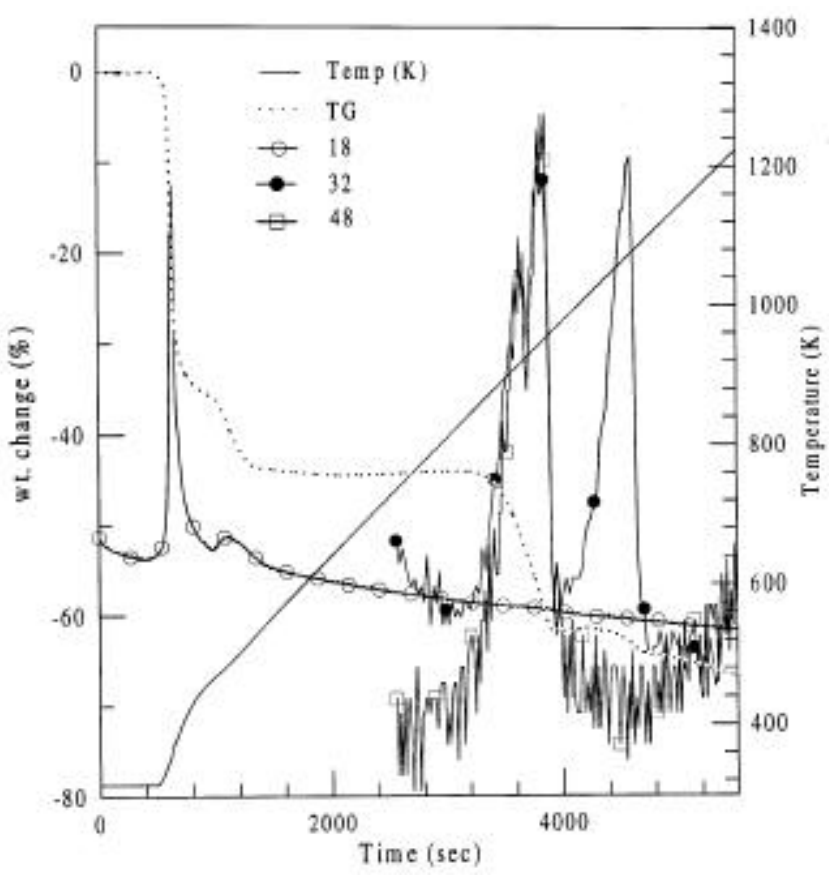

Figure 5. TGA-EGA-MS spectra of TPD of copper sulphate at optimized operating conditions.

\section{Results and discussion}

This system is being extensively used to study the temperature programmed decomposition of inorganic solids, their kinetics and reaction mechanisms. The TGA-EGA-MS spectra were generated by plotting the continuous change of sample weight and ion intensities of product gases as a function of time and/or specimen temperature. In addition to discern various reaction stages and their temperature regimes, the EGA-MS data was also used to compute the fractional extent ' $\alpha$ ' of various reaction stages. The ' $\alpha$ ' vs ' $T$ ' values thus deduced were used with non-isothermal kinetic expressions to arrive at the reaction control mechanisms and the corresponding kinetic parameters like activation energy and pre-exponential factors (Gadalla 1985; Dash et al 1997a, 1998). With the knowledge of the various reaction stages, the temperature programmed decomposition was interrupted at appropriate temperatures, upon completion of each reaction stage (by monitoring the MS signal of the corresponding gas to fall to background) to generate the reaction intermediates and final product. These residual products were subsequently subjected to off-line analysis by XRD, XPS, FT-IR and high resolution TEM. With this complementary information, complete structural-chemical transformations occurring in the course of thermal process could be mapped out.

In addition to studying the model substances to standardize and optimize the system performance (Kamruddin et al 1997), the decomposition of aluminum ammonium sulphate (alum - a double salt) (Kamruddin et al 1996), cobalt ethylene diamine complexes (Dash et al 1999a), cerium nitrate (Kamruddin et al 2001), thorium carbonate (Dash et al 2002) and technologically relevant materials like uranyl nitrate hexahydrate (Dash et al 1999b), thorium nitrate pentahydrate (Dash et al 2000a), thorium oxalate hexahydrate (Dash et al 2001), which are important precursors encountered in the back end of the nuclear fuel reprocessing, are also studied. In most of the above substances the TPD results in the formation of nanocrystalline products.

\subsection{TPD of thorium nitrate}

Temperature programmed decomposition of a number of inorganic solids were studied and as a typical result, our studies on thorium nitrate pentahydrate $\left(\mathrm{Th}\left(\mathrm{NO}_{3}\right)_{4} \cdot 5 \mathrm{H}_{2} \mathrm{O}-\right.$ $\mathrm{ThN}$ ) is presented here. ThN was investigated to understand (i) the stoichiometric transformation to product thoria, (ii) evolution of product stoichiometry in terms of oxygen to metal ratio, (iii) thermokinetic analysis of various conversion stages through application of non-isothermal kinetics and (iv) to deduce the complete reaction pathway.

GR grade ThN powder (Merck KgaA, Germany) is used in this study. A typical TGA-EGA-MS spectra of 
the sample taken in the temperature range 300-1200 K at a heating rate of $6 \mathrm{~K} / \mathrm{min}$ is shown in figure 6 , with markings showing temperatures at which the reaction intermediates were withdrawn for subsequent analyses. The bimodal dehydration occurs in the temperature range $325-525 \mathrm{~K}$ and extends well beyond the initiation of denitration step. The denitration step occurs in the temperature range $425-825 \mathrm{~K}$ and contains three substages with various extent of $\mathrm{NO}_{x}$ release. The multi-step dehydration and denitration indicate the crystallographic inequivalence and can be explained by the different hydrogen bonding schemes and $\mathrm{N}-\mathrm{O}$, Th-O bond distances for various nitrate groups. The fractional extent of reaction, obtained from mass spectrometry data, was used for non-isothermal kinetic analysis to obtain the rate controlling mechanisms and the associated arrhenius parameters of various reaction stages. They are given in table 1 .

Using the gas release information obtained from EGAMS data, the TGA weight loss profile was mathematically deconvoluted into four substages with percentage weight changes of $6 \cdot 3,27.9,14.6$ and 4.6 , respectively and each substage could be properly assigned to dehydration, concomitant dehydration and denitration followed by denitration and decomposition of residual nitrate.

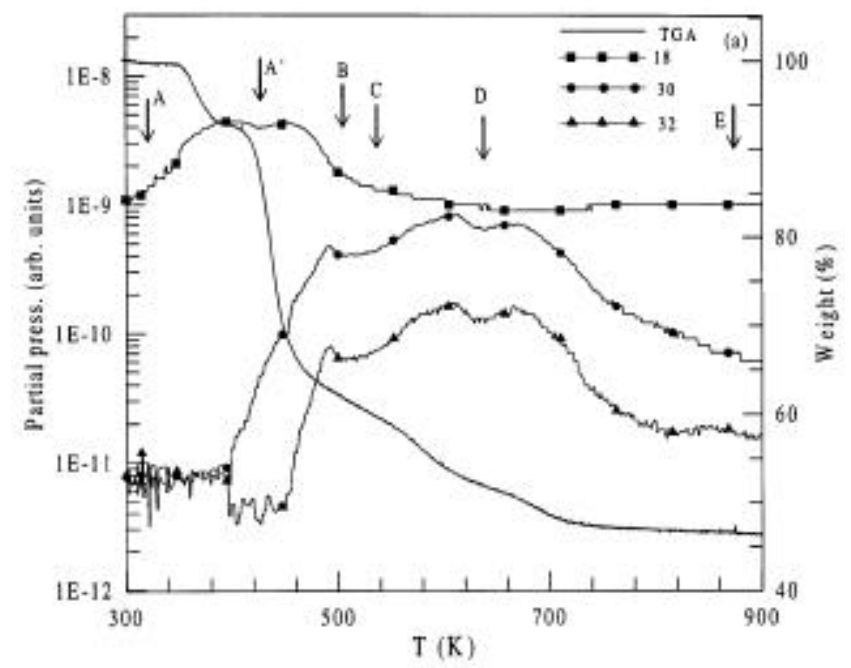

Figure 6. TGA-EGA-MS spectra of TPD of thorium nitrate.
The corresponding XRD pattern of the ThN and the product intermediates are shown in figures $7 \mathrm{a}-\mathrm{e}$. The stoichiometric balancing has shown that the reaction intermediate at $505 \mathrm{~K}$ to be a hydroxynitrate, $\mathrm{Th}(\mathrm{OH})_{1+x}$ $\left(\mathrm{NO}_{3}\right)_{2}$ (figure $7 \mathrm{~b}$ ). As no match was found in JCPDSICDD, a least square fitting procedure (TREOR) was employed for structure determination. Thus this pattern was indexed to an orthorhombic unit cell with smaller unit cell dimension than the parent nitrate. The reduction of volume can be attributed to the release of various functional groups and the higher ionicity of the hydroxyl group. The residue at $540 \mathrm{~K}$ also showed a similar XRD pattern (figure 7c) but with a reduced intensity. Stoichiometric balancing indicated the formation of an oxynitrate, $\mathrm{ThO}\left(\mathrm{NO}_{3}\right)_{2}$ phase. The residue at $650 \mathrm{~K}$ showed broad Bragg peaks (figure 7d), indicating the compound to be $\mathrm{X}$ ray amorphous. The structural collapse may be due to complete loss of hydrogen bonding. The peak positions indicated formation of nanocrystalline $\mathrm{ThO}_{2}$. Advancement of temperature program to $900 \mathrm{~K}$ resulted in complete decomposition of this amorphous intermediate and agglomeration of nanocrystallites to microcrystalline thoria (figure 7e).

With the backing of above information, the XPS analysis of $\mathrm{ThN}$ and reaction intermediates was carried out in VG ESCALAB MX 200X ESCA machine using Al- $\mathrm{K}_{\alpha}$ $\mathrm{X}$-ray source, by recording the $\mathrm{Th}\left(4 f_{7 / 2}\right), \mathrm{O}\left(l_{\mathrm{S}}\right)$ and $\mathrm{C}\left(l_{\mathrm{S}}\right)$ (as internal reference to correct sample charging) to probe the temperature program induced changes in the chemical environment around the Th metal atom and the $\mathrm{O} / \mathrm{M}$ ratio (Dash et al 2000a). The $\mathrm{O}\left(l_{\mathrm{S}}\right)$ peaks were found to be a convolution of three different peaks arising out of three distinctly different chemical environments for oxygen, viz. O-H, O-N and O-Th. The observed increase in $\mathrm{O}-\mathrm{H}$ contribution to the overall O-peak of the residue at $525 \mathrm{~K}$, substantiates the formation of a hydroxynitrate intermediate. Though the oxidation state of Th remained unchanged at +4 , the change in the chemical shift and the position of the satellite peaks, indicated the continuous change in the chemical coordination around Th metal atom. The oxygen to metal ratio $(\mathrm{O} / \mathrm{M})$ obtained from the XPS data showed a systematic decline from 17 (molecular structural value) to $2 \cdot 2$ with increasing temperature. The stoichiometry arrived from TGA measurements were thus substantiated by XPS studies.

Table 1. Reaction mechanism, corresponding correlation coefficients, activation energy and preexponential factors for various reaction stages during the decomposition of $\mathrm{Th}\left(\mathrm{NO}_{3}\right)_{4} \cdot 5 \mathrm{H}_{2} \mathrm{O}$.

\begin{tabular}{lcccc}
\hline Reaction stage & $\begin{array}{c}\text { Rate controlling } \\
\text { mechanism }\end{array}$ & $\begin{array}{c}\text { Correlation } \\
\text { coefficient }\end{array}$ & $\begin{array}{c}\text { Activation energy } \\
(\mathrm{kJ} / \mathrm{mol})\end{array}$ & $\begin{array}{c}\text { Pre-exponential } \\
\text { factors }\left(\mathrm{sec}^{-1}\right)\end{array}$ \\
\hline Dehydration: I (AA') & A1 & 0.991 & 34.25 & $1.98 \times 10^{3}$ \\
Dehydration: II (A'B) & D3 & 0.999 & $50 \cdot 79$ & $2.68 \times 10^{3}$ \\
Denitration: I (BC) & D3 & 0.983 & 95.49 & $3.871 \times 10^{6}$ \\
Denitration: II (CD) & A1 & 0.999 & $35 \cdot 36$ & $50 \cdot 5$ \\
Denitration: III (DE) & D3 & 0.999 & 59.39 & 911 \\
\hline
\end{tabular}




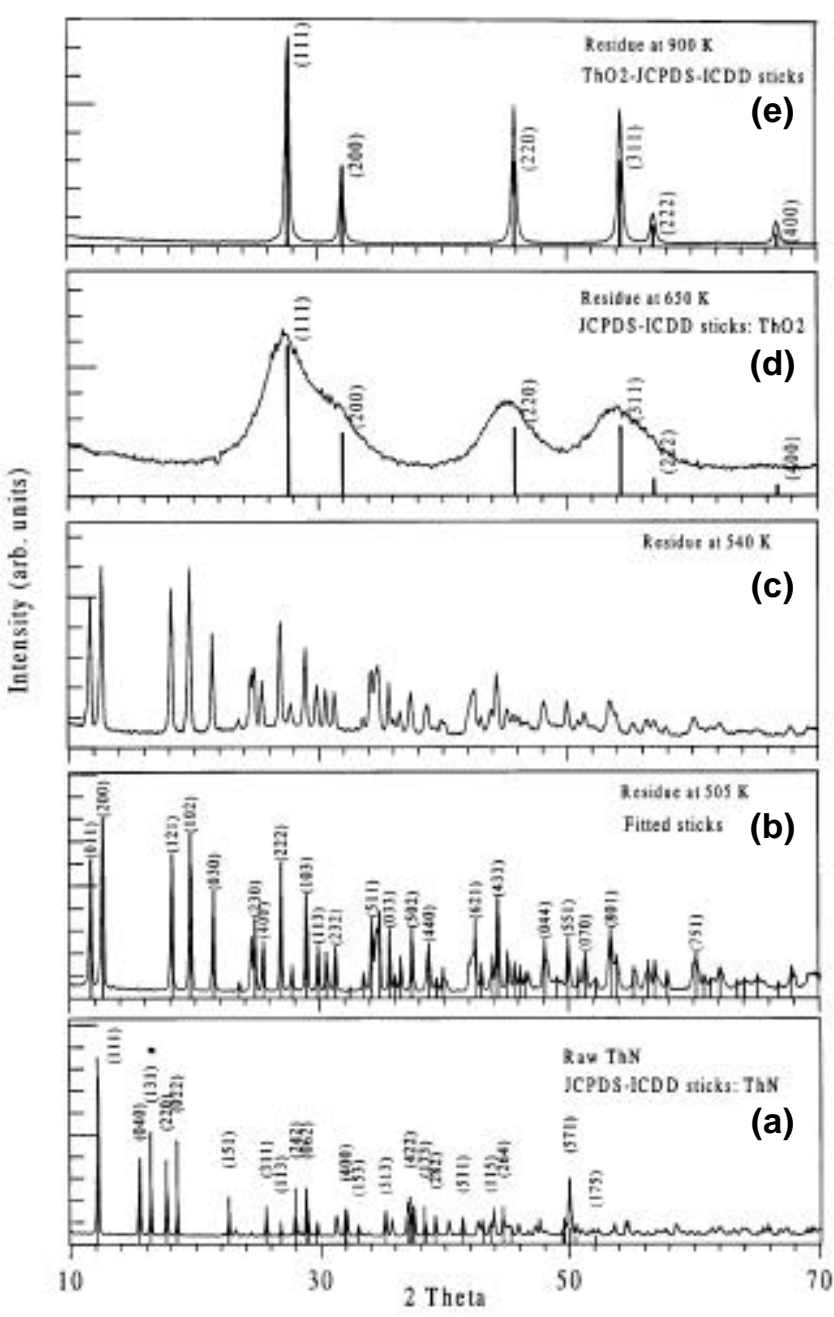

Figure 7. Powder XRD patterns with matching JCPDS-ICDD/ fitted sticks of (a) raw $\mathrm{ThN}$, (b) hydroxy nitrate, (c) oxynitrate, (d) nanocrystalline thoria and (e) microcrystalline thoria.

From the observations and inferences made from this study, the reaction pathway for the temperature programmed decomposition of $\mathrm{ThN}$ is given as follows:

$$
\begin{aligned}
& \mathrm{Th}\left(\mathrm{NO}_{3}\right)_{4} \cdot 5 \mathrm{H}_{2} \mathrm{O} \rightarrow \mathrm{Th}\left(\mathrm{NO}_{3}\right)_{4} \cdot 3 \mathrm{H}_{2} \mathrm{O} \rightarrow \mathrm{Th}(\mathrm{OH})_{1+x}\left(\mathrm{NO}_{3}\right)_{2} \\
& 400 \mathrm{~K} \\
& \mathrm{ThO}_{2} \stackrel{900 \mathrm{~K}}{\longleftarrow} \mathrm{ThO}_{2} \stackrel{650 \mathrm{~K}}{\longleftarrow} \mathrm{ThO}_{1+x}\left(\mathrm{NO}_{3}\right)_{1-y} \leftarrow \mathrm{ThO}\left(\mathrm{NO}_{3}\right)_{2} \\
& \text { (microcrystalline) (nanocrystalline) }
\end{aligned}
$$

\subsection{Formation of nanocrystalline materials}

Temperature programmed decomposition in vacuum condition of many oxyanion based inorganic substances like carbonates, sulphates and nitrates yielded their respective nanocrystalline oxides as the reaction intermediate/end products. The formation of nanocrystalline materials may be attributed to the non-equilibrium nature of the nonisothermal mode and the dynamic high vacuum of EGA-
MS operating conditions. This is further assisted by the release of misfit strain energy from the disregistry of the reactant/product interface.

Transmission electron microscopy and analysis of XRD peak broadening using Scherrer formulation are used to find the average particle size of these nanocrystallites (Suryanarayana and Norton 1998). Observed peak broadening is a convolution of instrumental effects, crystallite size and lattice strain. After eliminating other contributions from the observed peak width, the crystallite size can be determined by

$$
B_{\text {crystallite }}=k \lambda / L \cos \theta,
$$

where $k=$ constant $\sim 0.94, \lambda$ the incident $\mathrm{X}$-ray wavelength, $B$ the angular width in terms of $2 \theta, L$ the average crystallite size in the direction perpendicular to the reflection plane and $2 \theta$ the Bragg angle subtended at the maximum intensity.

A systematic TPD study of calcite has revealed formation of metastable nanocrystalline calcia under vacuum conditions whereas calcite decomposition in flowing helium gas resulted in formation of stable microcrystalline calcia (Dash et al 2000b). TEM analysis of partially decomposition calcite and in situ observation of its further decomposition under electron beam bombardment in the vacuum of TEM column indicated this transformation to occur via two mechanisms (Alok Singh et al 2002). The XRD pattern of metastable and nanocrystalline $\mathrm{CaO}$ obtained from vacuum decomposition of calcite $\left(\mathrm{CaCO}_{3}\right)$ having particle size around $17 \mathrm{~nm}$ is shown in figure 8a. The high resolution TEM micrograph with corresponding SAD pattern are shown in figure 9. However, decomposition in air or helium produced a stable microcrystalline $\mathrm{CaO}$.

The vacuum decomposition of aluminum ammonium sulphate has also resulted in formation of nanocrystalline $\gamma-\mathrm{Al}_{2} \mathrm{O}_{3}$ (figure $8 \mathrm{~b}$ ) through formation of nano aluminum sulphate as intermediate. The particle size of nano alumina was found to be around $4 \mathrm{~nm}$. Nanocrystalline $\mathrm{ThO}_{2}$ could be obtained by the vacuum thermal decomposition of $\mathrm{ThN}$ and thorium oxalate (Dash et al 2001). The crystallite sizes of $\mathrm{ThO}_{2}$ obtained were about $3 \mathrm{~nm}$ and $7 \mathrm{~nm}$, respectively. Their XRD patterns are shown in figures $8 \mathrm{c}$ and d. A similar study on vacuum decomposition of cerium(III) nitrate hexahydrate, yielded nanocrystalline $\mathrm{CeO}_{2}$ (figure $8 \mathrm{e}$ ), with crystallite size around $9 \mathrm{~nm}$. The particle sizes were also verified by TEM.

\subsection{Analysis of gas mixtures}

This system is also being used to analyse unknown gas mixtures and purity of gases. In addition to identification of gaseous components and their isotopic purities, it can also provide quantitative information through proper calibration by analysing mixtures of known compositions. 
This aspect finds immense application in analysing reactor cover gas and plenum fission gas samples from irradiated nuclear fuel pins. The variation in their relative isotopic abundance will be an indicator to the fuel burnup.

For calibration, ultra high pure gases $(99.995 \%)$ are used to prepare gas mixtures of varying compositions. For example, to measure ppm level of $\mathrm{O}_{2}$ impurity in $\mathrm{He}$, we started with a gas mixture of $2 \%$ of $\mathrm{O}_{2}$ in $\mathrm{He}$ $\left(\sim 20000 \mathrm{ppm}\right.$ of $\mathrm{O}_{2}$ in $\left.\mathrm{He}\right)$. This original mixture was successively diluted with high purity $\mathrm{He}$ gas to prepare mixtures with lower concentrations of $\mathrm{O}_{2}$ in $\mathrm{He}$. This step was repeated to get an $\mathrm{O}_{2}$ level down to $12 \mathrm{ppm}$ in $\mathrm{He}$. Mass spectrometric data was acquired at each stage and analysed for $\mathrm{He}$ and $\mathrm{O}_{2}$. The calibration plot prepared from this data is shown in figure 10. The calibration plot shows good linearity and systematic trend. This plot was used to analyse unknown high purity He samples for ppm levels of $\mathrm{O}_{2}$ impurity.

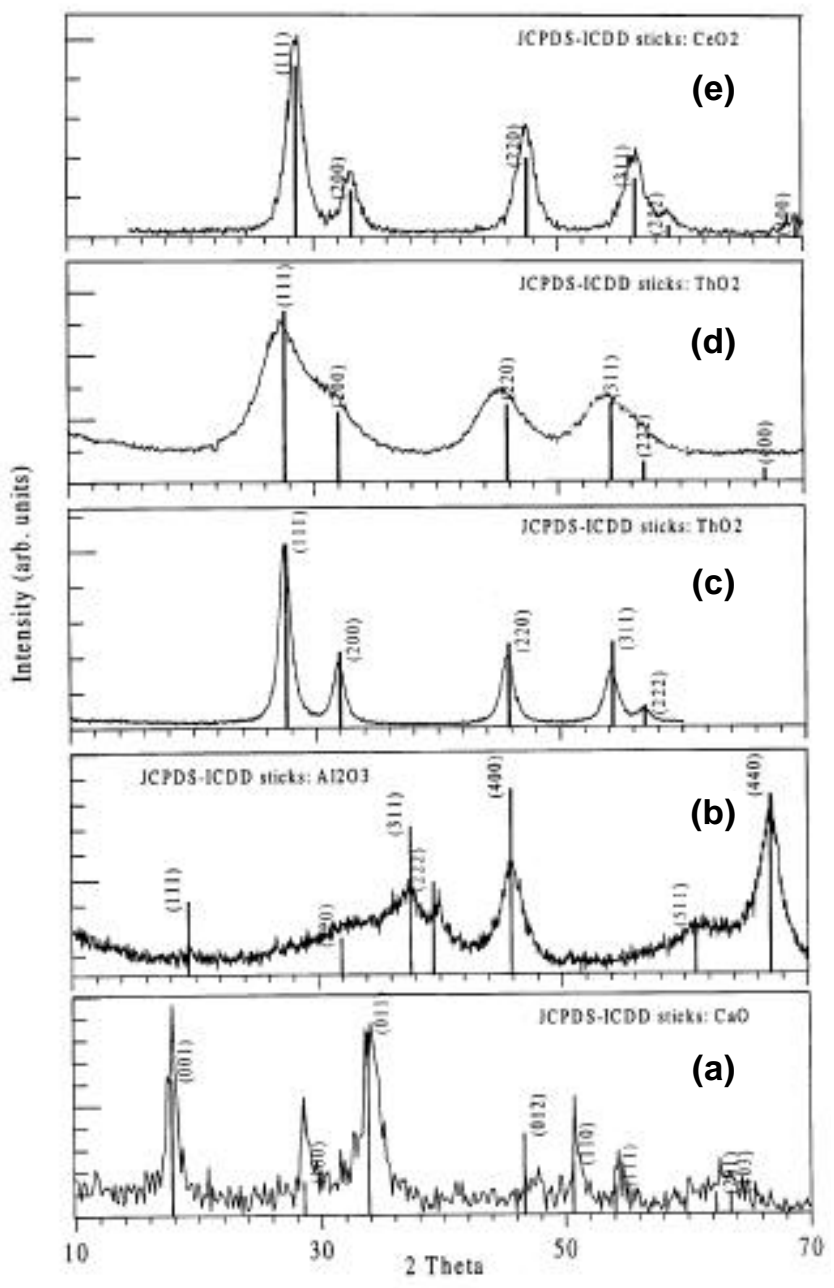

Figure 8. Powder XRD patterns with matching JCPDS-ICDD sticks of (a) calcia, (b) alumina, (c) thoria from $\mathrm{ThN}$, (d) thoria from thorium oxalate and (e) ceria.

\subsection{Oxide/nitride overlayers by controlled atmosphere exposures}

Oxide, nitride, oxynitride overlayers can be grown on metallic/alloy substrates by exposing them to flowing $\mathrm{O}_{2}$, $\mathrm{N}_{2}$ or $\mathrm{NH}_{3}$, NO, respectively with or without inert dilution (Franchy 2000). In case of carbide overlayers, CO or $\mathrm{CH}_{4}$ is used as carbon source and $\mathrm{H}_{2}$ as reducer (Medeiros et al 2001). The adsorbed $\mathrm{O}_{2}$ obtained from $\mathrm{CO}$ decomposition is removed from the substrate surface by the reaction with $\mathrm{H}_{2}$ or $\mathrm{CO}$. The gas mixtures having required compositional ratio can be prepared in the MFC based delivery system. The weight gain, consumption of reactants and release of product gases can be continuously monitored (Waime et al 1998) to study the growth modes, mechanism, intermediate species encountered and growth kinetics. In addition, this can be used for in situ oxidation/ corrosion studies. As e.g. figure 10 shows the dynamic secondary ion mass spectrometry (SIMS) depth profile of Inconel-601 (a nickel base super alloy) specimen exposed to flowing nitrogen stream at $1273 \mathrm{~K}$ for $40 \mathrm{~h}$ (Dash et al 1997b). The figure shows the intensities of the molecular ion species $\left(\mathrm{CsX}^{+}\right.$, where $\mathrm{X}=\mathrm{Ni}, \mathrm{Cr}, \mathrm{Fe}, \mathrm{Mn}, \mathrm{Si}, \mathrm{Cu}, \mathrm{Al}$, $\mathrm{O}$ and $\mathrm{N}$ ) as a function of sputter depth and indicates a two-step nitridation with considerable surface segregation of $\mathrm{Cr}$ and $\mathrm{Mn}$ (Dash et al 1997c). The GI-XRD pat-

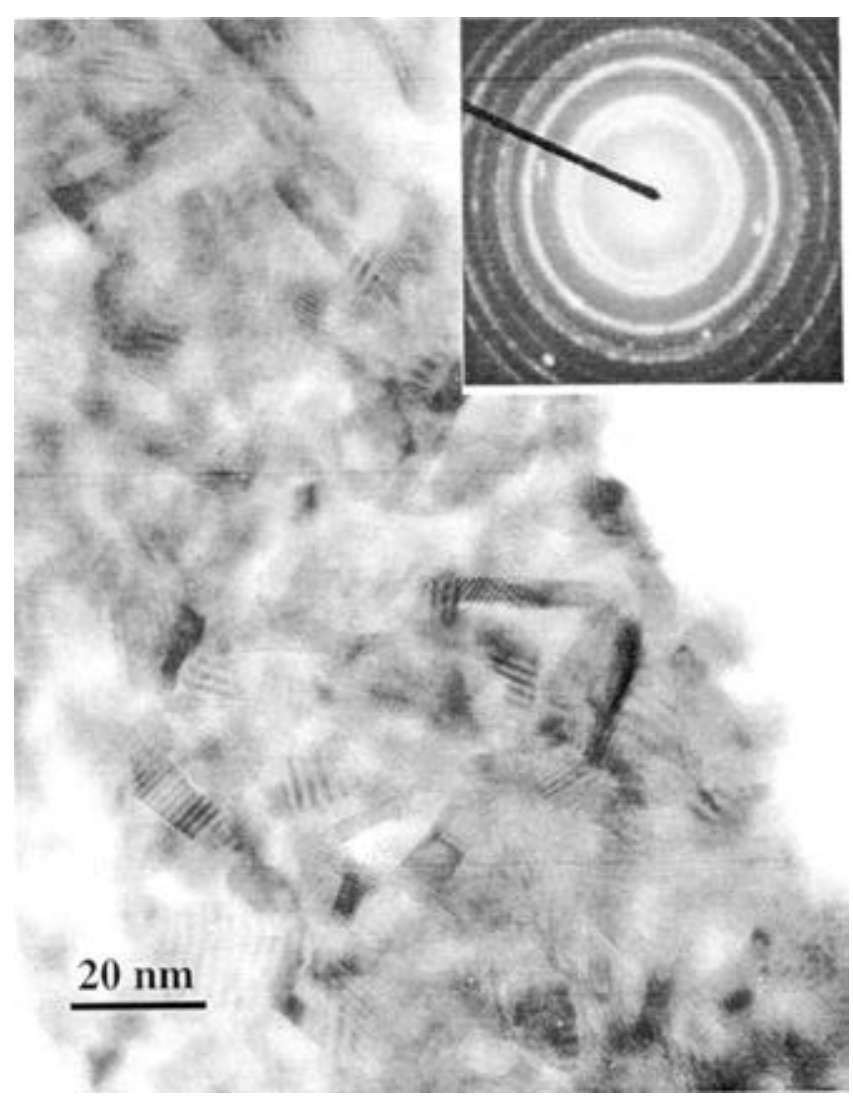

Figure 9. HR-TEM micrograph with corresponding SAD pattern of nano calcia obtained by vacuum thermal decomposition. 
tern acquired at an incidence angle of $1^{\circ}$ of this specimen oxidized at $1073 \mathrm{~K}$ for $20 \mathrm{~h}$ is shown in figure $10 \mathrm{~b}$. The modified region mainly consisted of a coherent protective

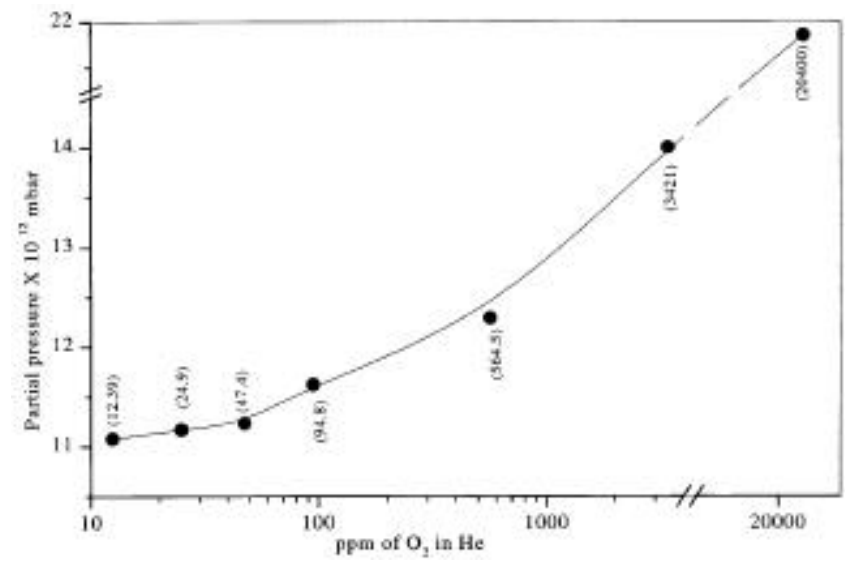

Figure 10. Calibration plot showing variation in partial pressure with decreasing oxygen content in pure helium gas.
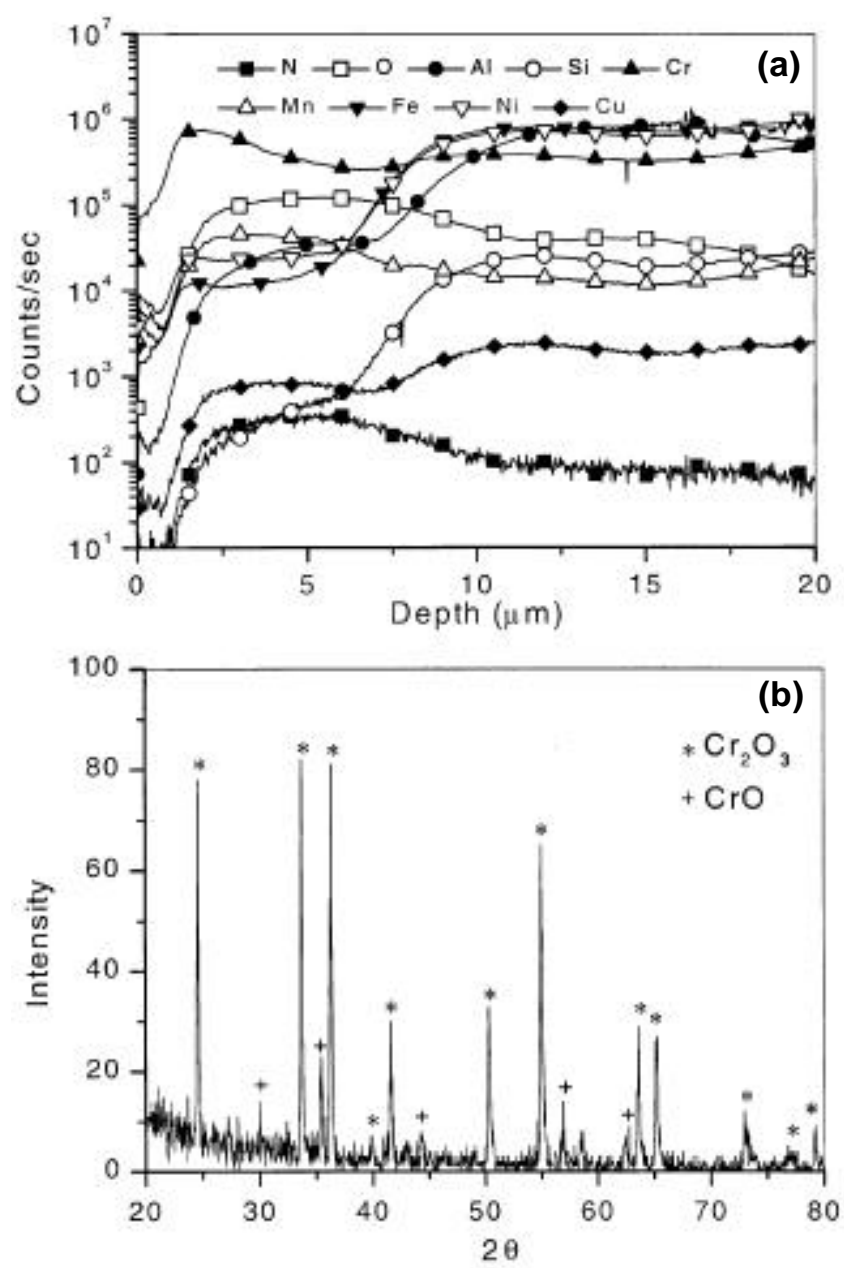

Figure 11. a. Dynamic SIMS depth profile of Inconel-601 exposed to flowing nitrogen at $1273 \mathrm{~K}$ for $40 \mathrm{~h}$ and b. GI-XRD pattern of Inconel-601 exposed to flowing oxygen at $1073 \mathrm{~K}$ for $20 \mathrm{~h}$, acquired at $1^{\circ}$ incident angle. layer of $\mathrm{Cr}_{2} \mathrm{O}_{3}$. The mechanism of formation of these protective oxide layers can be derived by conducting sequential exposures with isotopically labeled oxygen $\left(\mathrm{O}^{16}\right.$ and $\left.\mathrm{O}^{18}\right)$ and nitrogen $\left(\mathrm{N}^{14}\right.$ and $\left.\mathrm{N}^{15}\right)$.

\section{Conclusion}

A versatile and modular ultra high vacuum compatible TGA-EGA-MS system has been set-up with additional features like MFC controlled gas/vapour delivery system and pulse free liquid delivery system. The UHV operating conditions and other differential pressure and flow conditions resulted in high sensitivity, low background and detection limits with minimum time delay and memory effects. This system is used to study temperature programmed decomposition of many oxyanion based inorganic salts. In conjunction with off-line analytical techniques, the chemical, structural evolution of the intermediates/products with complete kinetic/reaction pathways are determined. The non-equilibrium nature of the EGA-MS operating condition assisted formation of nanocrystalline materials in the decomposition of many systems. This facility can also be used to study high temperature gas solid interactions, as controlled environment exposure facility for high temperature oxidation/corrosion studies and also for preparing carbide and nitride overlayers and novel coatings.

\section{Acknowledgements}

The authors are thankful to Dr B Purniah and Shri J Jayapandian for instrumentation support, to Dr V S Sastri, Dr G V N Rao and Shri G L N Reddy for acquisition of XRD patterns, Dr Alok Singh for HR-TEM, Dr Santanu Bera for XPS analysis and R Krishnan for Inconel oxidation and nitridation work.

\section{References}

Akermark Torbjorn 1998 Oxid. Met. 50167

Alok Singh, Dash S, Kamruddin M, Ajikumar P K, Tyagi A K, Raghunathan V S and Baldev Raj 2002 J. Am. Ceram. Soc. 85927

Barnes P A 1987 Thermochim. Acta 1141

Brown Micheal E 1998 Handbook of thermal analysis, Principles and practice (New York: Elsevier) Vol. 1, p. 509

Charsley E L, Manning N J and Warrington S B 1987 Thermochim. Acta 11447

Dash S, Kamruddin M and Tyagi A K 1997a Bull. Mater. Sci. 20359

Dash S, Krishnan R, Rajagopalan S and Tyagi A K 1997b Proc. int. conf. corrosion and its control (CONCORN97), Mumbai (eds) A S Khanna et al (Amsterdam: Elsevier) p. 939

Dash S, Krishnan R, Paulraj M, Balamurugan A K, Rajagopalan S, Kamruddin M and Tyagi A K 1997c Proc. symp. localized corrosion and environmental cracking (Kalpakkam: IGCAR) (compiled by H S Khatak and S Rajendran Pillai), p. C-30 
Dash S, Kamruddin M, Ajikumar P K, Krishnan R and Tyagi A K 1998 Indian J. Chem. Technol. 535

Dash S, Ajikumar P K, Kamruddin M and Tyagi A K 1999a Thermochim. Acta 334141

Dash S, Kamruddin M, Santanu Bera, Ajikumar P K, Tyagi A K, Narasimhan S V and Baldev Raj 1999b J. Nucl. Mater. 264271

Dash S, Kamruddin M, Ajikumar P K, Tyagi A K, Baldev Raj, Santanu Bera and Narasimhan S V 2000a J. Nucl. Mater. 278 173

Dash S, Kamruddin M, Ajikumar P K, Tyagi A K and Baldev Raj 2000b Thermochim. Acta $\mathbf{3 6 3} 129$

Dash S, Krishnan R, Kamruddin M, Tyagi A K and Baldev Raj 2001 J. Nucl. Mater. 295281

Dash S, Alok Singh, Ajikumar P K, Subramanian H, Rajalakshmi M, Tyagi A K, Arora A K, Narasimhan S V and Baldev Raj 2002 J. Nucl. Mater. 303156

Dollimore D, Gamlen G A and Taylor T J 1984 Thermochim. Acta 7559

Franchy R 2000 Surf. Sci. Rep. 38195

Fremory J K and Boden K 1978 J. Phys. E11 106

Gadalla A M 1985 Thermochim. Acta 95179

Gallagher P K 1982 J. Thermal Anal. 257

Gorte R J 1996 Catal. Today 28405

Heide K, Gerth K, Buchel G and Hartmann E 1997 J. Thermal Anal. 4873

Heide K, Hartmann E, Gert K and Wiedemann H G 2000 Thermochim. Acta 365147

Janakiraman R, Meier G and Pettit F S 1999 Metall. Mater. Trans. A30 2905

Jedlinski J and Borchardt G 1991 Oxid. Met. 36317

Jemal M and Khattech I 1989 Thermochim. Acta 15265

Kaisersberger E and Post E 1997 Thermochim. Acta 29573

Kamruddin M, Ajikumar P K, Dash S, Purniah B, Tyagi A K and Krishan K 1995 Instrum. Sci. Technol. 23123

Kamruddin M, Ajikumar P K, Dash S, Krishnan R, Tyagi A K and Krishan K 1996 Thermochim. Acta 28713
Kamruddin M, Ajikumar P K, Dash S, Krishnan R, Tyagi A K and Krishan K 1997 J. Thermal Anal. 48277

Kamruddin M, Shemet V, Singheisiser L, Tyagi A K and Quadakkers W J 2000 Proc. of international symp. on materials aging and life management, Kalpakkam (New Delhi: Allied Publishers Limited) p. 815

Kamruddin M, Ajikumar P K and Tyagi A K 2001 Workshop on complete cycle characterization of materials, Kalpakkam

Kamruddin M, Ajikumar P K, Dash S and Tyagi A K 2002 IGCAR News Letter $\mathbf{5 1} 7$

Leskela T, Lippmaa M, Niinisto L and Soininen P 1993 Thermochim. Acta 2149

Maciejewski M and Baiker A 1997 Thermochim. Acta 29595

Medeiros F F P, De Oliveria S A, De Souza C P, Da Silva A G P, Gomes U U and De Souza J F 2001 Mater. Sci. \& Eng. A315 58

Mullens J, Carleer R, Reggers G, Yperman J, Vanhees J and Van Poucke L C 1992 Thermochim. Acta 212219

Mullens J, Reggers G, Rusen M, Carleer R,Yperman J, Vanhees J, Franko D and Van Poucke L C 1997 J. Thermal Anal. 491061

Nielsen M, Jurasek P, Hayashi J and Furimsky E J 1995 Anal. Appl. Pyrol. 3543

Ohrbach Karl-Heinz, Radhoff Gabriele and Kettrup Antonius 1983 Thermochim. Acta 67189

Ozawa Takeo 2000 Thermochim. Acta 352-353 177

Price D, Dollimore D, Fatemi N S and Whitehead R 1980 Thermochim. Acta $\mathbf{4 2} 323$

Raemaekers K G H and Bart J C J 1997 Thermochim. Acta 2951

Remmler M, Kopinke F-D and Stottmeister U 1995 Thermochim. Acta 263101

Statheropoulos M and Kyriakou S A 2000 Anal. Chim. Acta 409203

Suryanarayana C and Norton M G 1998 X-ray diffraction: A practical approach (New York: Plenum) p. 207

Waime H, Centeno M A, Picard S, Bastians P and Grange P 1998 J. Eur. Ceram. Soc. 181293 